\title{
Manufacturing and characterization of similar to foam steel components processed through selective laser melting
}

\author{
Fabrizia Caiazzo $^{1}$ - Sabina Luisa Campanelli ${ }^{2}$. Francesco Cardaropoli ${ }^{1}$. \\ Nicola Contuzzi ${ }^{2} \cdot$ Vincenzo Sergi $^{1} \cdot$ Antonio Domenico Ludovico $^{2}$
}

Received: 28 November 2016/Accepted: 15 March 2017 / Published online: 28 March 2017

(C) The Author(s) 2017. This article is published with open access at Springerlink.com

\begin{abstract}
The growing interest from the industry for lightweight metal components has driven the development of processes that would allow creating lightweight high melting point metals as steels, able to guarantee mechanical characteristics superior to existing foam (typically aluminium), without penalizing one of the characteristics that cell structures have: lightness. Conventional manufacturing methods, such as casting, however, face difficulty in making complex periodic steel structures with designed shape and size and volume fraction. This study evaluates the manufacturability and performance of lightweight 17-4 PH steel components with spherical porosity fabricated via selective laser melting (SLM). Samples were designed and fabricated with the purpose to produce a structure similar to foam. Built samples were characterized in terms of dimensional accuracy, mechanical strength under compression and energy absorbed per unit mass. The designed structures have a designed relative density or volume fraction ranging between 31.1 and $32.8 \%$.
\end{abstract}

Keywords Selective laser melting · Additive manufacturing · Stainless steel $\cdot$ Lightweight structures $\cdot$ Steel foam

Fabrizia Caiazzo

f.caiazzo@unisa.it

1 Dip. di Ingegneria Industriale - Università degli Studi di Salerno, Via Giovanni Paolo II 132, 84084 Fisciano, SA, Italy

2 Dipartimento di Meccanica, Matematica e Management, Politecnico di Bari, Viale Japigia, 182 Bari, Italy

\author{
Abbreviations \\ D Diameter of sample [mm] \\ $d_{1} \quad$ Pore diameter $[\mathrm{mm}]$ \\ $d_{2} \quad$ Pore diameter [mm] \\ $d_{\text {asb }} \quad$ As-built sample diameter [mm] \\ $d_{\text {eff }} \quad$ Measured diameter after sandblasting [mm] \\ $E_{\mathrm{c}} \quad$ Elastic compressive modulus [GPa] \\ $L \quad$ Height of sample [mm] \\ $V_{b} \quad$ Bounding volume $\left[\mathrm{mm}^{3}\right]$ \\ $V_{\text {eff }} \quad$ Effective volume $\left[\mathrm{mm}^{3}\right]$ \\ $W_{\text {md }} \quad$ Energy absorbed per unit mass $[\mathrm{MJ} / \mathrm{kg}]$ \\ $W_{\mathrm{vd}} \quad$ Energy absorbed per unit volume $\left[\mathrm{MJ} / \mathrm{m}^{3}\right]$ \\ $\Delta \quad$ Error $[\mu \mathrm{m}]$ \\ $\varepsilon_{d} \quad$ Densification strain [\%] \\ $\rho_{r} \quad$ Designed volume fractions [\%] \\ $\rho_{\text {reff }} \quad$ Measured relative density [\%] \\ $\sigma_{\mathrm{pl}} \quad$ Plateau stress [MPa]
}

\section{Introduction}

Selective laser melting (SLM) is a layer-based additive manufacturing process in which complex shape objects with intrinsic engineered features can be easily manufactured by selectively melting layers of powder under an inert atmosphere [1]. The possibility of producing high-level densification and high-performance metal parts, with mechanical properties comparable with those of components obtained with traditional processes, has focused research, in the past few years, on this technology, making it one of the most attractive additive manufacturing (AM) techniques.

The optimization of process parameters, in order to obtain almost full density and good mechanical properties of the bulk materials, represented the first step of the development of the 
Table 1 Chemical composition of 17-4 PH stainless steel (wt.\%)

\begin{tabular}{lllllllll}
\hline $\mathrm{Cr}$ & $\mathrm{Ni}$ & $\mathrm{Cu}$ & $\mathrm{Mn}$ & $\mathrm{Si}$ & $\mathrm{Mo}$ & $\mathrm{Nb}$ & $\mathrm{C}$ & $\mathrm{Fe}$ \\
\hline $15 \div 17.5$ & $3 \div 5$ & $3 \div 5$ & $1.0^{\mathrm{a}}$ & $1.0^{\mathrm{a}}$ & $0.5^{\mathrm{a}}$ & $0.15 \div 0.45$ & $0.07^{\mathrm{a}}$ & Bal.
\end{tabular}

${ }^{\mathrm{a}} \operatorname{Max}$

SLM technology and of the scientific production [2-4], but research in producing parts with customized porosity and higher performances is raising $[5,6]$. Porous materials are exploited in different sectors, ranging from biomedical to aerospace $[7,8]$.

Nowadays, SLM has been used to fabricate lightweight components because of the achievable component complexity that can be realized in comparison to conventional manufacturing processes [9].

Metal cellular structures are a unique classification of materials, which can exhibits a combination of high-performance features such as high strength accompanied by a relatively low mass, good energy absorption characteristics and good thermal and acoustic insulation properties. These structures are classified into two common types: stochastic porous structures and periodic cellular lattice structures. Metal stochastic porous structures typically have a random distribution of open or closed voids, whereas lattice structures present uniform structures that are generated by repeating a unit cell. Therefore, metal periodic cellular lattice structures can be used to develop structures with advanced or multifunctional performance for high value engineering products. These periodic lattice structures, however, currently face a higher manufacturing complexity and costs than the stochastic structures [10]. It can be time and cost consuming to use conventional methods (i.e. investment casting, deformation forming, metal wire approaches, brazing, etc.) to make periodic cellular lattice structures. The structures made by conventional methods possess relatively simple geometries and limited design freedom and consequently lack advanced functionality to meet more advanced requirements and applications.

SLM has the capability of producing structures of complex freeform geometry. It has been demonstrated to manufacture cellular lattice structures with fine features, showing a great potential to make advanced lightweight structures and products that are highly desired by engineering sectors such as aerospace, automotive and medical industries [8]. However, SLM requires support structure to build an overhang section if its angle from the horizontal is less than a certain degree. This introduces design and manufacturing complications for the SLM of lightweight cellular structures and engineering components. The cellular lattice structures with a large unit cell size or low strut angles from the horizontal (usually lower than $30^{\circ}$ ) could not be built using the SLM process because overhanging struts led to the occurrence of serious deformation [11].

In this paper, the feasibility of manufacturing lightweight steel structures with spherical porosity adopting SLM process and their properties has been studied. Samples were designed and fabricated with the purpose to produce a structure similar to foam. Steel foam materials have a great potential both in structural and non-structural applications spacing from mechanical, aerospace and automotive domains.

As reported by Smith et al. [12], significant research has been performed regarding optimal manufacturing methods for foams made of metals, such as aluminium, titanium and copper, but steel presents unusual challenges, including a higher melting point, that require new technology. Several manufacturing methods have been developed such as powder metallurgy, which has been successfully used to create structural steel foam prototypes in hollow spheres, Lotus-type [13].

Further research in developing and testing new materials and new manufacturing processes is still required. No literature was found on the fabrication and characterization of steel foam by SLM.

EOS 17-4 PH stainless steel powder has been used, employing an EOSINT M270 laser sintering system with optimized exposure parameters to obtain full density of laser-sintered parts. Precipitation-hardened (PH) stainless steels have been widely used as structural materials and related applications in marine environments, power plants (light water and pressurized water reactors) and chemical industries because of their good
Fig. 1 a, b SEM images of the 17-4 $\mathrm{PH}$ alloy powder at different scales
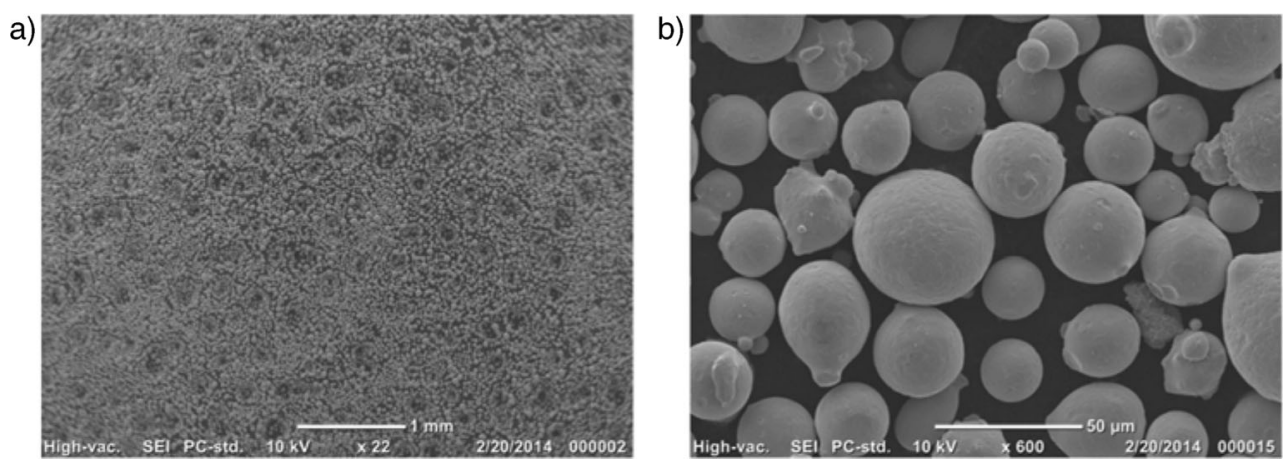
Table 2 Mechanical properties of 17-4 PH stainless steel

\begin{tabular}{lllll}
\hline $\begin{array}{l}\text { Ultimate tensile strength } \\
{[\mathrm{MPa}]}\end{array}$ & $\begin{array}{l}\text { Yield strength } \\
{[\mathrm{MPa}]}\end{array}$ & $\begin{array}{l}\text { Young's modulus } \\
{[\mathrm{GPa}]}\end{array}$ & $\begin{array}{l}\text { Elongation at break } \\
{[\%]}\end{array}$ & $\begin{array}{l}\text { Hardness } \\
{\left[\mathrm{HV}_{1}\right]}\end{array}$ \\
\hline 850 & 530 & 170 & 25 & 230 \\
\hline
\end{tabular}

mechanical properties and corrosion resistance at typical service temperatures below $300{ }^{\circ} \mathrm{C}$ [14]. Commercially important stainless steels can be austenitic or martensitic, and this phase composition fundamentally controls the mechanical properties of the material. With SLM, 17-4 stainless steel can be produced in either phase depending on powder composition, SLM conditions and post-build heat treatment [15]. Starr et al. [16] demonstrated that EOS powder, in combination with protective nitrogen atmosphere, caused in SLM as-built products the formation of metastable austenite, because nitrogen is known to be an "austenite stabilizer".

Previous investigations with stainless steel using SLM have reported various results and applications of lattice or porous structures made of 316 L [17-19], whereas research on precipitation hardening steel is quite limited [20]. Studies on SLM stainless steel structure as core material in sandwich construction showed that this material has significant potential that merits further examination and analysis. Twin skinned, sandwich structures are of interest for application for aerospace structures found in fuselage, wing and other components. Such structures have advantages over monolithic shells, such as improved specific bending stiffness and strength, and multifunction potential, e.g. acoustic and thermal properties [17]. In this paper, different topology structures have been studied. The performance of these structures have been analysed in terms of dimensional accuracy, mechanical strength under compression and energy absorbed per unit mass.

\section{Experimental procedure}

\subsection{Materials}

The periodic porous structures were made from a 17-4 PH alloy powder, which was purchased from Electro Optical System (EOS) GmbH, Germany. A powder with a mean particle size of $20 \mu \mathrm{m}$ has been used in this investigation, and alloy chemical composition is listed in Table 1. The powder quality is important to reduce the content of impurities (oxygen, hydrogen and nitrogen), which might negatively affect mechanical properties of laser-sintered parts with phenomena like embrittlement.

Figure 1 depicts the SEM images of the 17-4 PH alloy powder at different scales. The powder has a nearly spherical shape and smooth surfaces, which lead to a good flowability. Table 2 highlights 17-4 PH stainless steel mechanical properties.

\subsection{Design of similar to foam structures}

Concerning the geometry, this manufacturing technique presents two main constraints. The former is due to the minimum track, which the laser beam is able to create. Considering the features of the machine adopted in this investigation, the threshold value is $200 \mu \mathrm{m}$ equal to the size of the melted zone with a single spot as proved by the previous test. The latter is relative to the lowest angle between the part and building platform. Some papers in literature highlighted that angles less than $45^{\circ}$ have to be avoided, in order to not have issues
Fig. 2 a Layer type A. b Layer type B
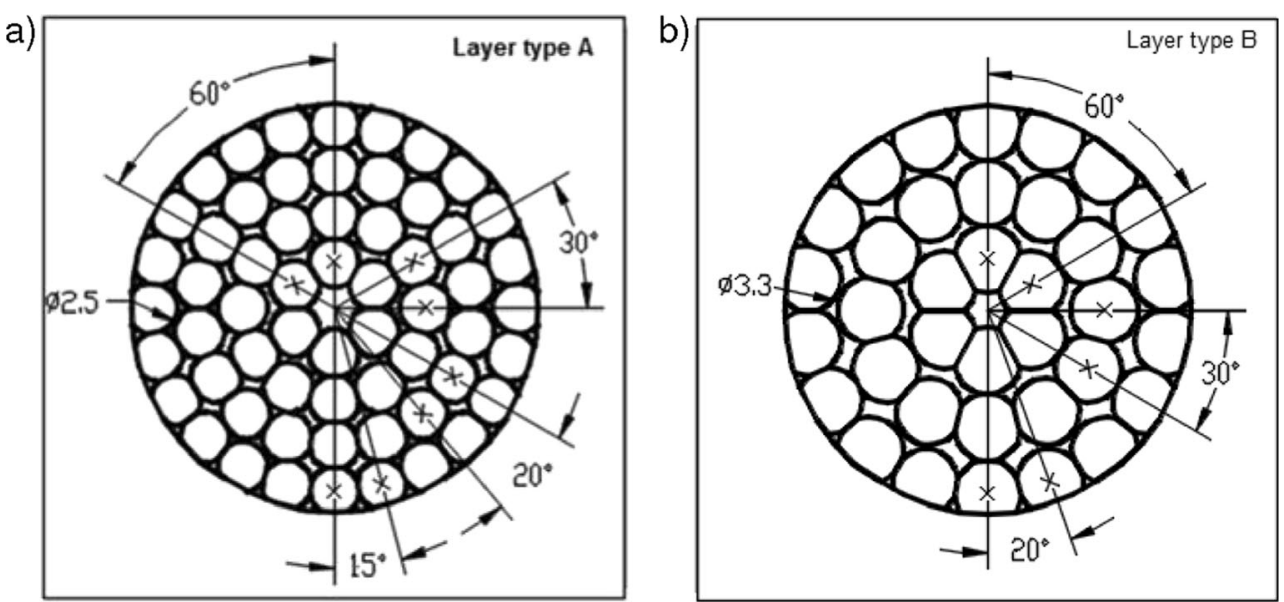


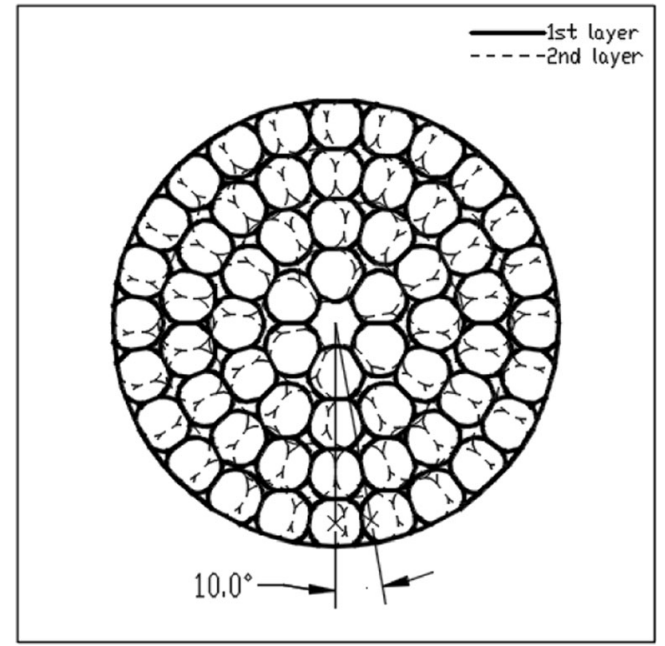

Fig. 3 Rotation in sample 2

connected with stability of the laser-sintered parts [11, 21]. Indeed, small angles cause a minimal overlap between each layer with possible issues during the recoating phase.

Several superimposed pore layers of two different types (type A and type B, Fig. 2) characterize the porous structures. The layer type A has 60 pores, with a diameter of $2.5 \mathrm{~mm}$, arranged in four circular crowns. Starting from the centre of the sample, the first crown has six pores arranged at an angular distance of $60^{\circ}$, the second has 12 pores at $30^{\circ}$, the third 18 pores at $20^{\circ}$ and the fourth has 24 pores at $15^{\circ}$. The layer type $\mathrm{B}$ has 36 pores, with a diameter of $3.3 \mathrm{~mm}$, arranged in three circular crowns. The first of them near the centre of the sample has six pores arranged at an angular distance of $60^{\circ}$, the second has 12 pores at $30^{\circ}$ and the third has 18 pores at $20^{\circ}$. All the pores are interconnected allowing the discharge of the powders at the end of the process.

Sample 1 has eight pore layers, four of type A alternated with four of type B, while samples 2 and 3 have 10 layers of only type A. The layers of sample 2 are rotated at $10^{\circ}$ (Fig. 3), while in sample 3 , there is no rotation in the layers.

Table 3 enlists the features of the samples, whereas Fig. 4 shows the three combinations of samples, which have a designed relative density $\left(\rho_{\mathrm{r}}\right)$ ranging from 31.1 to $32.8 \%$.

\subsection{Fabrication of samples by SLM}

Porous structures have been manufactured using an EOSINT M270 titanium version laser sintering system, and every

Table 3 Plan used for the experimental phase

\begin{tabular}{llllll}
\hline Sample & $L[\mathrm{~mm}]$ & $D[\mathrm{~mm}]$ & $d_{1}[\mathrm{~mm}]$ & $d_{2}[\mathrm{~mm}]$ & $\rho_{\mathrm{r}}[\%]$ \\
\hline 1 & 20.0 & 20.0 & 3.3 & 2.5 & 32.8 \\
2 & 20.0 & 20.0 & 2.5 & - & 31.1 \\
3 & 20.0 & 20.0 & 2.5 & - & 32.3 \\
\hline
\end{tabular}

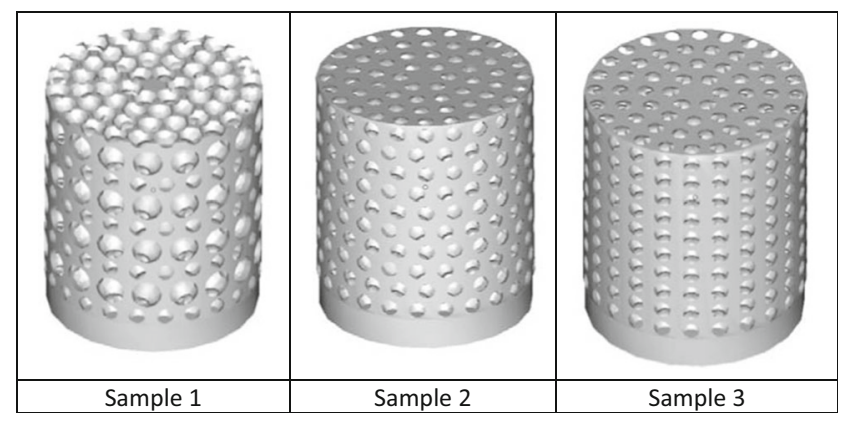

Fig. 4 Cell topologies of the three samples

configuration has been repeated twice. Machine specifications are given in Table 4.

During the manufacturing phase, the model is sliced into thin layers whose thickness is $20 \mu \mathrm{m}$. Within the production chamber, the fabrication is carried out in a controlled nitrogen atmosphere with percentages of oxygen lower than $0.8 \%$ to avoid oxidation during sintering. The stainless steel powder from the dispenser is moved by the recoater and spread to the building platform, where powder bed is selectively melted by the laser beam. Later, the dispenser is lifted up to give material for a new layer and the building platform is lowered by the thickness of one layer. These operations are repeated until the fabrication is completed.

The exposure parameters for manufacturing the samples have been chosen in order to obtain full density of lasersintered part and are summed up in Table 5. These parameters influence energy density, which is a key factor in SLM, to avoid an excessive melting of the layers and ensure adhesion between successive layers, with an adequate penetration, as observed by Cardaropoli et al. [22].

\subsection{Dimensional measurements and mechanical characterization}

To carry out the analysis of the samples, dimensional measurements have been performed. As literature pointed out, additive technologies did not ever allow the precise replication of the model with possible changes in porosity content and mechanical behaviour; therefore, accuracy is considered a key aspect in this study. The specimens have been measured using a

Table 4 EOSINT M270 titanium version specifications

\begin{tabular}{ll}
\hline Effective building volume & $250 \times 250 \times 215 \mathrm{~mm}^{3}$ \\
Building speed & $2 \div 20 \mathrm{~mm}^{3} / \mathrm{s}$ \\
Layer thickness & $20 \div 100 \mu \mathrm{m}$ \\
Laser type & Yb-fibre \\
Maximum power & $200 \mathrm{~W}$ \\
Precisions optics & F-theta lens, high-speed scanner \\
Focused spot diameter & $0.090 \mathrm{~mm}$ \\
\hline
\end{tabular}


Table 5 Exposure parameters adopted for manufacturing the samples

\begin{tabular}{ll}
\hline Factor & Value \\
\hline Laser power & $195 \mathrm{~W}$ \\
Scan speed & $0.75 \mathrm{~m} / \mathrm{s}$ \\
Hatch spacing & $0.10 \mathrm{~mm}$ \\
Scan length & $20 \mathrm{~mm}$ \\
Layer thickness & $20 \mu \mathrm{m}$ \\
\hline
\end{tabular}

coordinate measuring machine (CMM) DEA Global Image Clima, with a maximum permissible micrometre error of $1.5+M / 333$, where $M$ is the measurement in millimetres. In order to perform analysis for top sample features, macrographs have been acquired via a Leica S8AP0 stereomicroscope and elaborated with Leica Application Suite software.

Compression tests were performed at room temperature under displacement control using an Instron 4467 machine equipped with a $200-\mathrm{kN}$ load cell; end-shortening was supplied to the specimen by setting compression speed to $0.5 \mathrm{~mm} /$ min. Specimens were tested along their build direction $(Z$ direction, as indicated in Fig. 5).

\section{Results and discussion}

\subsection{Visual inspections}

Figure 5 shows the built samples, one for each configuration, after the removal from the building platform.

Issues during the fabrication of the non-stochastic configurations were not apparent. It is seen that the struts of the porous structures are well manufactured by the SLM process, and the struts are solid, connected and continuous, although some defects have been observed with further analyses.

\subsection{Dimensional and stereomicroscope analysis of porous structures}

Measurements with CMM have been conducted on sintered parts as-built and after specimen sandblasting to remove partially molten particles. The CMM has been employed to perform metrological analysis and verify accuracy of
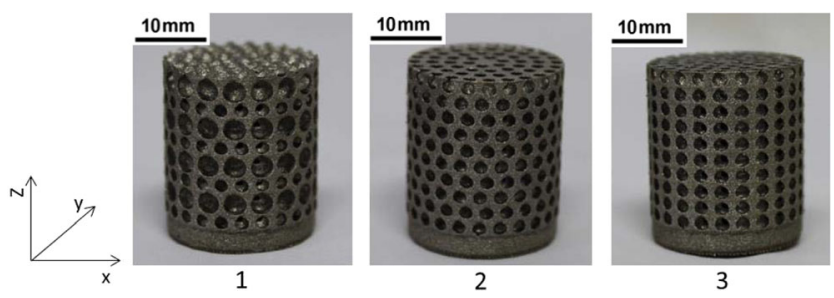

Fig. 5 Built samples, one for each configuration
Table 6 Results of metrological analysis

\begin{tabular}{lllcll}
\hline Sample & $D[\mathrm{~mm}]$ & $D_{\text {asb }}[\mathrm{mm}]$ & $\Delta[\mu \mathrm{m}]$ & $D_{\text {eff }}[\mathrm{mm}]$ & $\Delta[\mu \mathrm{m}]$ \\
\hline 1A & 20.0 & 20.009 & 9 & 19.939 & -61 \\
1B & 20.0 & 19.989 & -11 & 19.927 & -73 \\
2A & 20.0 & 20.000 & 0 & 19.943 & -57 \\
2B & 20.0 & 20.012 & 12 & 19.943 & -57 \\
3A & 20.0 & 20.002 & 2 & 19.971 & -29 \\
3B & 20.0 & 20.017 & 17 & 19.986 & -14 \\
\hline
\end{tabular}

manufacturing process. In particular, porous structures have been measured three times and their average values have been reported in Table 6, where $D_{\text {asb }}$ is the measure of the as-built sample diameter, $D_{\text {eff }}$ is the measure of the diameter after sandblasting and $\Delta$ the error in micrometer. It can be inferred that deviations from model dimensions are quite small in the as-built specimens, whereas, after the process of sandblasting, some measurements present deviations more than $50 \mu \mathrm{m}$, which is considered a reference value for part accuracy. Such an influence of sandblasting is due to minimum wall thickness of the samples, which favours removal.

A Leica S8AP0 stereomicroscope has been used to acquire macrographs of sample features: it is noticed that some lateral pores are not spherical and top holes on the boundary present bent features (Fig. 6). This phenomenon is connected with a small local size of porous structure features, which have not been properly supported by unmolten powder, resulting in the instability of laser-sintered part. Defects shown in Fig. 6b have also been magnified by sandblasting.

Using stereomicroscope macrographs elaborated with Leica Application Suite software, top diameters have been measured as shown in Fig. 7 for sample 1B. Table 7 reports the average values observed for diameters and the deviation from the theoretical dimensions is highlighted.

The high difference between CAD and measured values is connected both with features not supported by unmolten powder and sandblasting effect. The exam of the model sections (Fig. 8) explains the reason for a smaller deviation on sample 1 with respect to other specimens. It can be inferred that these specimens present smaller top features and a higher building angle, as highlighted in Fig. 8, which hinders layer fabrication and favours material removal.

\subsection{Evaluation of relative density}

Sintered specimens have been carefully removed from the working plate; then a milling process has been performed on the surface which was previously in direct contact with the support, in order to remove any burrs and to ease the evaluation of both geometric characteristics and density. Samples have been weighted using an Adventurer Pro Ohaus precision 
Fig. 6 Defects observed

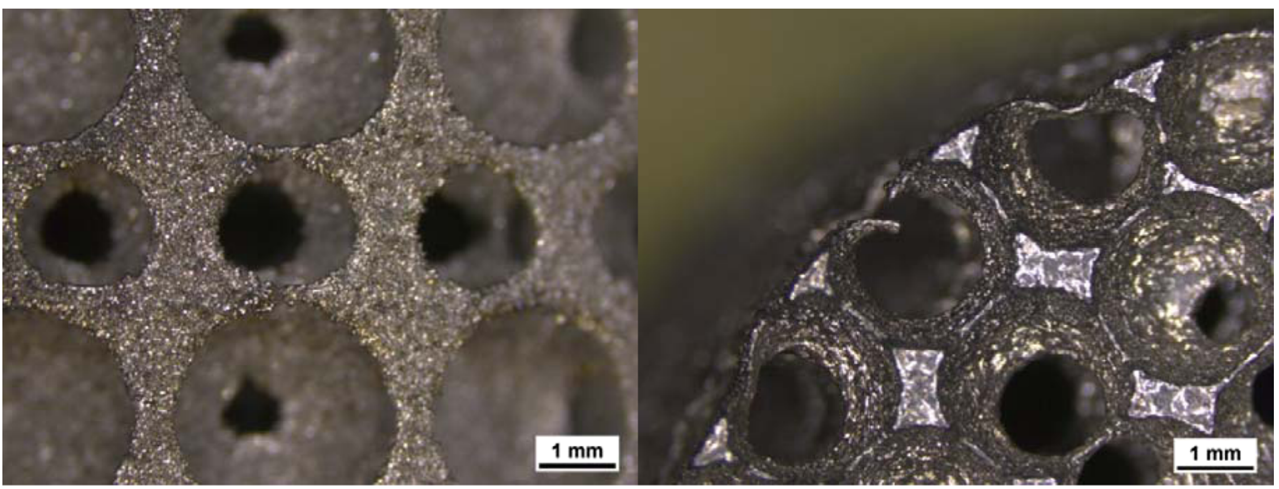

balance, therefore, effective volume of the porous structures $\left(V_{\text {eff }}\right)$ has been calculated as mass by bulk density ratio. By analysing the CMM results in terms of height and external diameter, the bounding volume $\left(V_{b}\right)$ of the porous structures has been determined, and then the experimental volume fractions of the SLM-manufactured lattice structures could be calculated. Indeed, effective relative density values $\left(\rho_{\text {reff }}\right)$ are evaluated as the ratio between $V_{\text {eff }}$ and $V_{b}$. The results are reported in Table 8 in comparison with designed volume fractions $\left(\rho_{r}\right)$.

The SLM-manufactured structures present measured relative density values lower with respect to the corresponding designed values. The difference between the theoretical and experimental volume fractions can be attributed to the reduction in the experimental strut size compared with the designed values. Appropriate beam compensation specification could lead to better dimensional accuracy by reducing the discrepancy between designed and as-built thicknesses; indeed, via software, it is possible to modify the laser trajectory followed

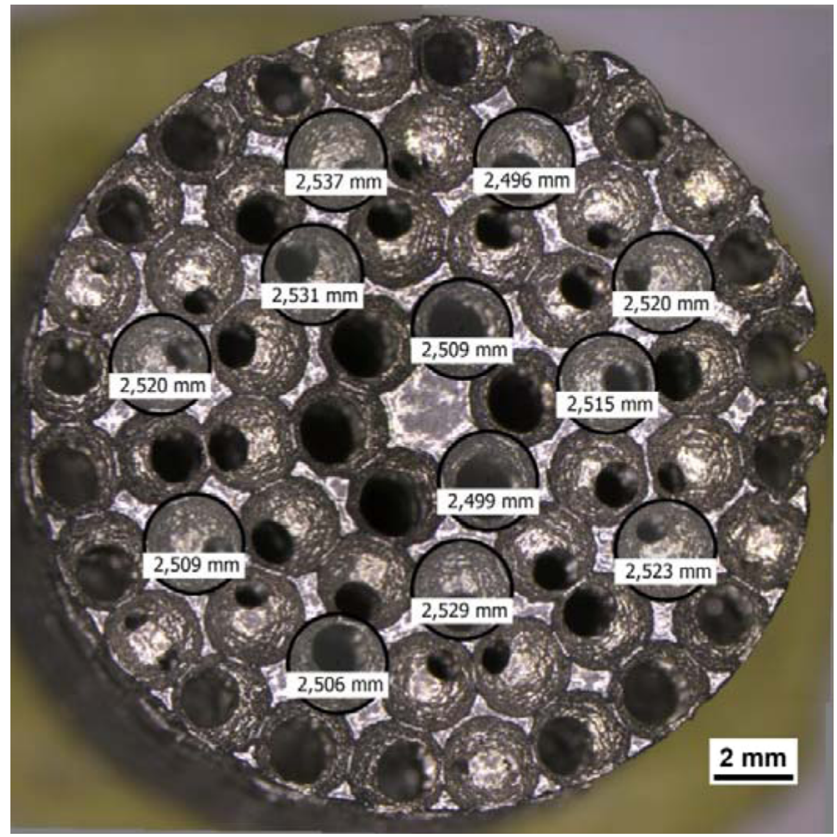

Fig. 7 Measurement of top diameters on sample 1B to create the part contour operating on beam compensation adding extra material which would be removed during the finishing process; furthermore, the geometry of the porous structures has to be modified to create self-supported struts to avoid bent features.

\subsection{Compression tests}

\subsubsection{Stress-strain behaviour}

Figure 9 shows stress-strain curves for the three samples, derived from the load-displacement curves recorded experimentally. The engineering stress and strain were determined according to ISO 13314 [23].

The stress-strain curves for samples 1 and 2 indicate an initially nearly linear elastic deformation range, followed by a long plateau region where plastic buckling occurs. The plateau stress is denoted by $\sigma_{\mathrm{pl}}$, which is at the end of the elastic regime. This was measured with an offset at a plastic strain of $2 \%$, according to Kaya et al. [24] and by McCullough et al. [25]. The plateau region ends when densification sets in, and when the opposing cell edges are completely compacted and crushed together. As a result, the stress-strain curve rises steeply at the so-called strain of densification strain $\varepsilon_{\mathrm{d}}$. This was determined as the intersection of tangents drawn in the plateau and densification regions of the stress-strain curve [24]. Sample 3 displays a different behaviour. After an initial region of linear elasticity, it exhibits a plateau region until a

Table 7 Results of stereomicroscope analysis for top diameters

\begin{tabular}{llll}
\hline Sample & $d[\mathrm{~mm}]$ & $d_{\text {eff }}[\mathrm{mm}]$ & $\Delta[\mu \mathrm{m}]$ \\
\hline 1A & 2.468 & 2.525 & 57 \\
1B & 2.468 & 2.514 & 46 \\
2A & 1.5 & 1.706 & 206 \\
2B & 1.5 & 1.727 & 227 \\
3A & 1.5 & 1.739 & 239 \\
3B & 1.5 & 1.75 & 250 \\
\hline
\end{tabular}


Fig. 8 Sections of samples 1 and 3

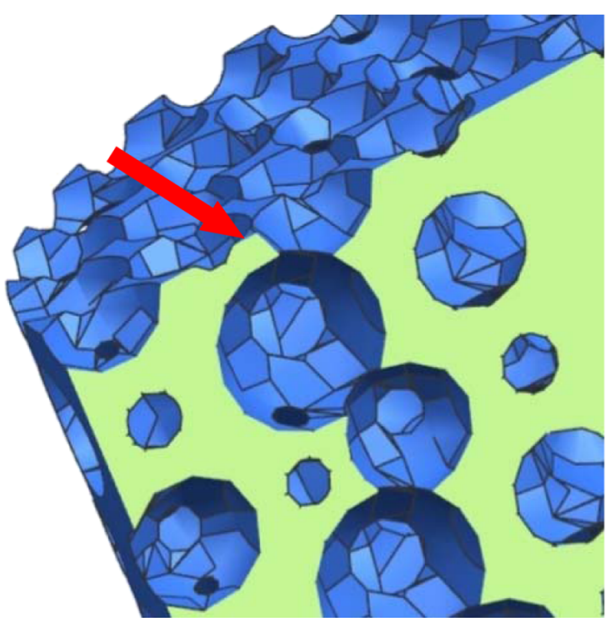

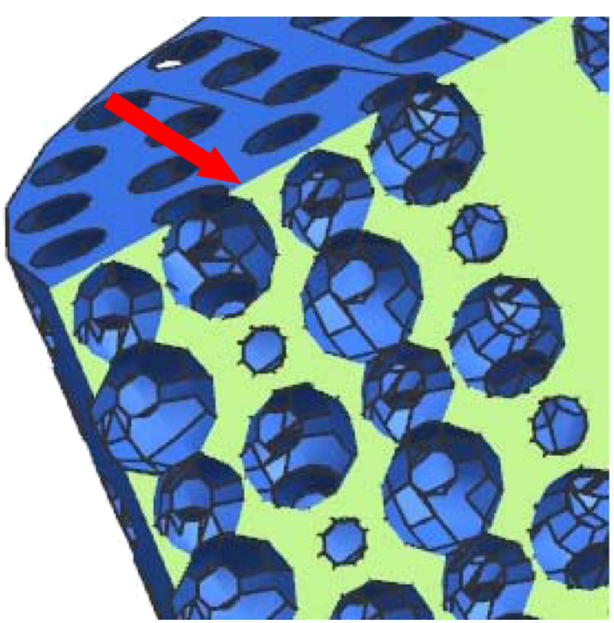

relative peak compressive strength. Continued loading resulted in a plastic collapse until breaking and densification.

Densification starts when the plastic plateau ends. This region is characterized by a complex deformation pattern. The stress required for the densification rises rapidly as the open spaces between the collapsed cell structures close up.

\subsubsection{Mechanical properties}

The mechanical properties, i.e. elastic compressive modulus $\left(E_{\mathrm{c}}\right)$, plateau stress and densification strain of all specimens are summarized in Table 9. It can be observed that the elastic compressive modulus is almost similar for all samples. Average values of the $E_{\mathrm{c}}$ range between 4.61 and $4.80 \mathrm{GPa}$.

The plateau stress is almost the same for samples 1 and 3 (between 97.2-97.3 MPa), but it is lower for sample 2, having the lowest value of $68 \mathrm{MPa}$. Average values for densification strain show that sample 1 reaches faster the densification stage than samples 2 and 3. Sample 2, which has the lowest relative density, starts densification at the highest average strain of $65 \%$.

\subsubsection{Deformation behaviour}

The macroscopic deformation behaviour of samples 1A, 2A and 3A is presented in Figs. 10, 11 and 12. Strain images of

Table 8 Evaluation of effective relative density

\begin{tabular}{lllll}
\hline Sample & $V_{\text {eff }}\left[\mathrm{mm}^{3}\right]$ & $V_{b}\left[\mathrm{~mm}^{3}\right]$ & $\rho_{\text {reff }}[\%]$ & $\rho_{r}[\%]$ \\
\hline 1A & 1881 & 6257 & 30.1 & 32.8 \\
1B & 1849 & 6236 & 29.7 & 32.8 \\
2A & 1740 & 6276 & 27.7 & 31.1 \\
2B & 1705 & 6265 & 27.2 & 31.1 \\
3A & 1795 & 6273 & 28.6 & 32.3 \\
3B & 1858 & 6276 & 29.6 & 32.3 \\
\hline
\end{tabular}

sample 1A are shown at nominal strains of 1, 15, 30, 50 and $60 \%$ (Fig. 10). According to the stress-strain curve, the specimen at a strain of $1 \%$ is still in the elastic regime (Fig. 10a). In Figs. $10 \mathrm{~b}$, c, sample $1 \mathrm{~A}$ is at a strain of 15 and $30 \%$, respectively. In these conditions, sample A is in the plateau region, characterized by nearly constant growth of flow stress. At $15 \%$ of strain, a deformation of pores can be observed. The compressive stress, causing pores to bend, leads to a bending deflection of opposite sides of pores. The whole structure deforms progressively (at 30\% of strain bending is more pronounced) with nearly constant increase of flow stress versus a high strain, which becomes relevant in the last stage of deformation (densification stage) where the flow stress increases sharply and opposite sides of pores intrude (Figs. 10d, e).

Figure 11 shows deformation behaviour for sample $2 \mathrm{~A}$ at nominal strains of $12,25,43,49,60$ and $68 \%$. The structure deforms progressively with nearly constant flow stress till about 25\% where the structure starts to develop cracks probably due to the collapse of weak pores and the subsequent formation of deformation bands (manifest as stress oscillation in the stress-strain curve), as also suggested by Castro et al. [27]. Deformation bands reduce compressive strength and compromise the ability to absorb energy. At a deformation

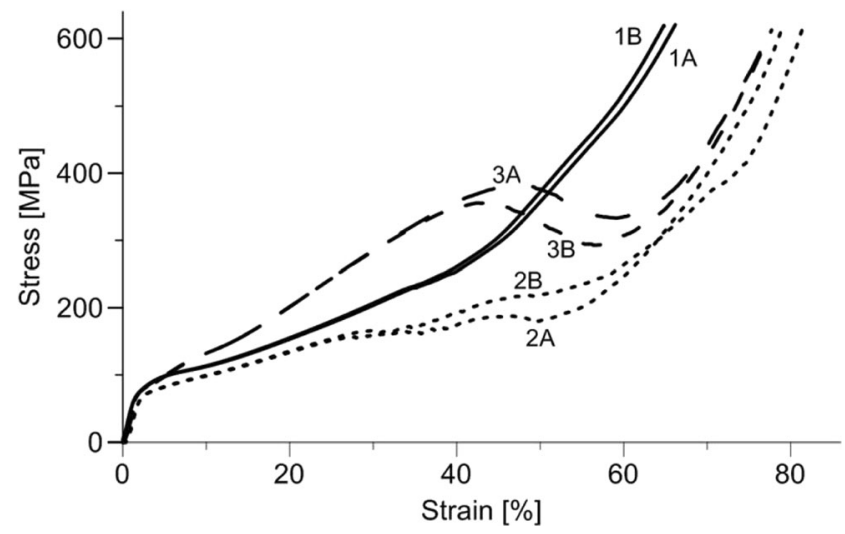

Fig. 9 Stress-strain curves for all samples 
Table 9 Mechanical properties of examined samples

\begin{tabular}{lllllcc}
\hline Sample & $\rho_{\text {reff }}[\%]$ & $E_{\mathrm{c}}[\mathrm{GPa}]$ & $\sigma_{\mathrm{pl}}[\mathrm{MPa}]$ & $\varepsilon_{\mathrm{d}}[\%]$ & $W_{\mathrm{vd}}\left[\mathrm{MJ} / \mathrm{m}^{3}\right]$ & $W_{\mathrm{md}}[\mathrm{kJ} / \mathrm{kg}]$ \\
\hline 1A & 30.1 & 4.73 & 97.3 & 49.6 & 91.99 & 39.20 \\
1B & 29.7 & 4.80 & 97.3 & 51.5 & 100.9 & 43.56 \\
Mean 1 & 29.9 & 4.77 & 97.3 & 50.6 & 96.45 & 41.35 \\
2A & 27.7 & 4.68 & 68.0 & 68.0 & 113.4 & 52.49 \\
2B & 27.2 & 4.75 & 68.0 & 62.0 & 101.8 & 47.98 \\
Mean 2 & 27.5 & 4.72 & 68.0 & 65.0 & 107.6 & 50.16 \\
3A & 28.6 & 4.73 & 97.2 & 58.0 & 148.1 & 66.39 \\
3B & 29.6 & 4.49 & 97.2 & 56.0 & 135.2 & 58.56 \\
Mean 3 & 29.1 & 4.61 & 97.2 & 57.0 & 141.6 & 62.41 \\
\hline
\end{tabular}

of about $43 \%$ (Fig. 11c), the development of shear bands is more pronounced and evident cracks appear in the shear direction. At 49\% (Fig. 11d), a local collapse of the whole structure occurs due to the elongation of cracks along the shear direction. Finally, at about $68 \%$ of strain (Fig. 11f), the compressed material densifies and the stress starts to increase again.

The deformation sequence of sample $3 \mathrm{~A}$ is observed in Fig. 12. At a strain of $1 \%$, the sample is still in the elastic regime and there is no plastic deformation visible (Fig. 12a). At a strain of $27 \%$ (Fig. 12b), the specimen is in the plateau region, with nearly constant increase of flow stress till a local maximum value at about $46 \%$ of strain (Fig. 12c). Later on it, the stress drops and nearly $45^{\circ}$ shear bands appear; a local collapse of the whole structure occurs due to the fracture of pores along the shear direction. Next, at about $58 \%$ of strain (Fig. 12d), the stress starts to increase again until full densification (Fig. 12e).

All samples, which have been designed to have similar relative density, have an effective average density ( $\left.\rho_{\text {reff }}\right)$ of $28.8 \%$ and an average porosity of $72.2 \%$, as shown in Section 3.3. The compressive elastic modulus is comparable a)

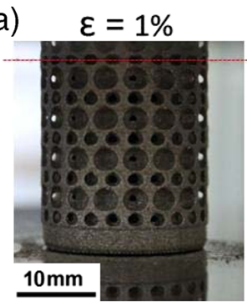

b)

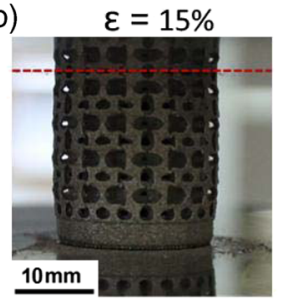

c)

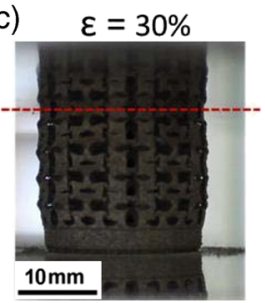

d) $\varepsilon=50 \%$

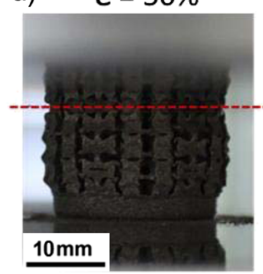

e) $\varepsilon=60 \%$

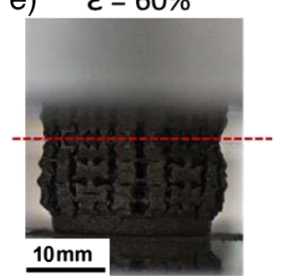

Fig. 10 Macroscopic deformations of sample $1 \mathrm{~A}$ at strains of a 1, b 15, c 30 , d 50 and e $60 \%$ for all samples. Average values of $E_{\mathrm{c}}$ range between 4.61 and $4.80 \mathrm{GPa}$. Thus, the very low difference of relative density between samples seems almost not having an effect on elastic modulus, but it has an appreciable effect on plateau stress that is observed to be about $30 \%$ lower in sample 2 than in samples 1 and 3 . On the other hand, stress-strain curves and the macroscopic deformations of samples suggest that the shape geometry significantly affects the deformation behaviour.

The performance of different materials for impact energy absorption can be compared by determining the strain energy absorbed during their compression up to densification [4]. The energy absorbed per unit volume $W_{\mathrm{v}}$ is given by the area under the stress-strain curve. Values of $W_{\mathrm{vd}}$ and of $W_{\mathrm{md}}$ (energy absorbed per unit mass) calculated till densification are listed in Table 9.

Sample 3 exhibits greater energy adsorption per unit volume than the other two specimens: 1.47 time more energy than sample 1 and 1.32 time more energy than sample 2 . The energy absorption capability is probably affected by the shape geometry of samples. In fact, sample 3 has a structure similar to lattice, with regular position of pores. Sample 3 has also the same pore diameter of sample 2 but a different location of pores.

The energy absorption values of the produced porous similar to foam SLM structures compare favourably to other energy absorbing cellular structures, such as syntactic steel

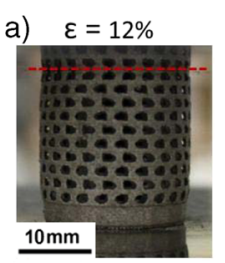

b) $\varepsilon=25 \%$

d)

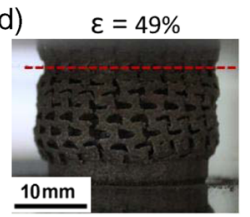

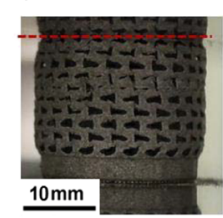

c) $\varepsilon=43 \%$

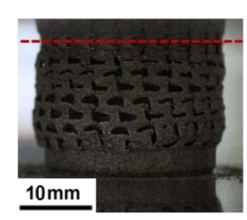

e)

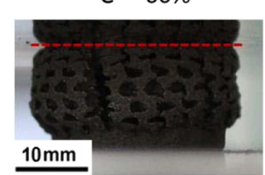

f)

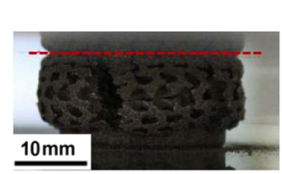

Fig. 11 Macroscopic deformations of sample 2A at strains of a 12, b 25, c 43 , d 49 , e 60 and f $68 \%$ 


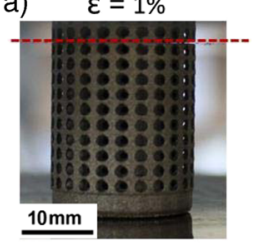

a) $\quad \varepsilon=1 \%$ b)

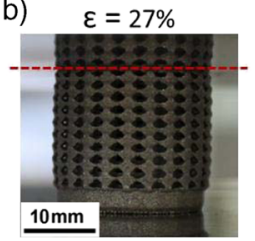

c) $\varepsilon=46 \%$

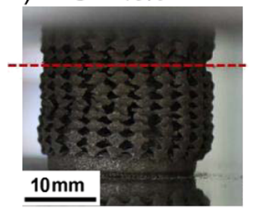

d) $\quad \varepsilon=58 \%$

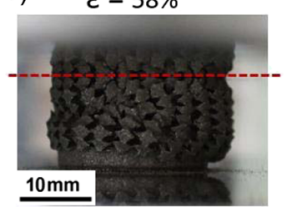

e) $\varepsilon=70 \%$

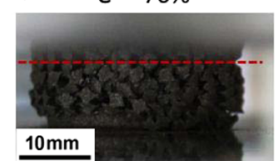

Fig. 12 Macroscopic deformations of sample $3 \mathrm{~A}$ at strains of a 1, b 27, c 46 , d 58 and e $70 \%$

foams [26], metallic trusses [27], egg-box structures [28] or composite steel foam [29]. For example, Castro et al. [26] found values of 39.15 and $29.2 \mathrm{~kJ} / \mathrm{kg}$ for syntactic steel foams with relative density of 60 and $46 \%$. Rabiei et al. [29] and Neville et al. [30] showed, for composite foams processed using both PM and casting techniques, values between 15.88 and $61.29 \mathrm{~kJ} / \mathrm{kg}$ with relative density ranging between 37.5 and $42.5 \%$. Similar to foam SLM structures exhibit energy absorbed per unit mass between 41.35 and $62.41 \mathrm{~kJ} / \mathrm{kg}$ with a relative density ranging from 27.5 to $29.9 \%$ (Fig. 13). Thus, similar to foam SLM parts reveal comparable or better energy absorption performances than other cellular structures with lower relative densities.

\section{Conclusions}

This paper has studied the possibility of manufacturing lightweight steel structures with spherical porosity adopting SLM technology. A stainless steel powder has employed, using an EOSINT M270 titanium version laser sintering system considering optimized parameters to have minimal content of porosity in laser-sintered parts.



Fig. 13 Energy absorption per unit mass vs. relative density: SLM steel foam, composite steel foam [29] and steel syntactic foam [26]
Different samples, having an effective average porosity ranging from 70.1 to $72.5 \%$ were successfully fabricated.

The SLM-manufactured structures presented measured relative density values lower in comparison with the corresponding designed values. The difference between the theoretical and experimental volume fractions can be attributed to the reduction in the experimental strut size compared with the designed values. Appropriate beam compensation specification could lead to dimensional accuracy by reducing the discrepancy between designed and as-built thicknesses; furthermore, the geometry of the porous structures has to be modified to create self-supported struts to avoid bent features.

Stress-strain curves and the macroscopic deformations of samples, that have similar average porosity, suggest that the shape geometry significantly affects the deformation behaviour. Sample 3 exhibits the best performance in terms of energy adsorption per unit mass at densification, reaching an average value of $141.6 \mathrm{MJ} / \mathrm{m}^{3}(62.41 \mathrm{~kJ} / \mathrm{kg})$. The produced porous similar to foam SLM structures exhibit comparable or better energy absorption per mass at densification performance than steel foams produced with other manufacturing processes, with the advantage of achieving lower relative densities and the possibility to design and control the internal structure of built parts.

Acknowledgements Authors are thankful to AITeM - PromozioneL@ser for supporting the research.

Open Access This article is distributed under the terms of the Creative Commons Attribution 4.0 International License (http:// creativecommons.org/licenses/by/4.0/), which permits unrestricted use, distribution, and reproduction in any medium, provided you give appropriate credit to the original author(s) and the source, provide a link to the Creative Commons license, and indicate if changes were made.

\section{References}

1. Agarwala M, Bourell D, Beaman J, Marcus H, Barlow J (1995) Direct selective laser sintering of metals. Rapid Prototyp J 1(1): 26-36

2. Kruth JP, Mercelis P, Van Vaerenbergh J, Froyen L, Rombouts M (2004) Selective laser melting of iron-based powder. J Mater Process Technol 149:616-622

3. Campanelli SL, Contuzzi N, Ludovico AD (2010) Manufacturing of $18 \mathrm{Ni}$ Marage 300 steel samples by selective laser melting. Adv Mater Res 83-86:850-857

4. Campanelli SL, Contuzzi N, Ludovico AD, Caiazzo F, Cardaropoli F, Sergi V (2014) Manufacturing and characterization of Ti6Al4V lattice components manufactured by selective laser melting. Materials 7(6):4803-4822

5. Hernandez-Nava E, Smith CJ, Derguti F, Tammas-Williams S et al (2015) The effect of density and feature size on mechanical properties of isostructural metallic foams produced by additive manufacturing. Acta Mater 85:387-395

6. Wauthle R, Vrancken B, Beynaerts B, Jorissen K, Schrooten J, Kruth JP, Van Humbeeck J (2015) Effects of build orientation and heat treatment on the microstructure and mechanical properties of 
selective laser melted Ti6A14V lattice structures. Additive Manufacturing 5:77-84

7. Contuzzi N, Campanelli SL, Casavola C, Lamberti L (2013) Manufacturing and characterization of 18Ni Marage 300 lattice components by selective laser melting. Materials 6:3451-3468

8. Cardaropoli F, Alfieri V, Caiazzo F, Sergi V (2012a) Manufacturing of porous biomaterials for dental implant applications through selective laser melting. Adv Mater Res 535-537:1222-1229

9. Yadroitsev I, Shishkovsky I, Bertrand P, Smurov I (2009) Manufacturing of fine-structured 3D porous filter elements by selective laser melting. Appl Surf Sci 255:5523-5527

10. Evans AG, Hutchinson JW, Fleck NA, Ashby MF, Wadley HN (2001) The topological design of multifunctional cellular metals. Prog Mater Sci 46:309-327

11. Brooks W, Sutcliffe C, Cantwell W, Fox P, Todd J, Mines R (2005) Rapid design and manufacture of ultralight cellular materials. In: Solid freeform fabrication symposium 2005 proceedings. Texas, Austin, pp 231-241

12. Smith BH, Szyniszewski S, Hajjar JF, Schafer BW, Arwade SR (2012) Steel foam for structures: a review of applications, manufacturing and material properties. J Constr Steel Res 71:1-10

13. Kremer K, Liszkiewicz A, Adkins J (2004) Development of steel foam materials and structures. US DOE and AISI final report DEFC36-97ID13554 performed by Fraunhofer USA-Delaware Center for Manufacturing and Advanced Materials, Newark, DE.

14. Leslie WC (1981) The physical metallurgy of steels. McGraw-Hill, New York

15. Murr LE, Martinez E, Hernandez J, Collins S, Amato KN, Gaytan SM, Shindo PW (2012) Microstructures and properties of 17-4 PH stainless steel fabricated by selective laser melting. Journal of Materials Research and Technology 1(3):167-177

16. Starr TL, Rafi K, Stucker B, Scherzer CM (2012) Controlling phase composition in selective laser melted stainless steels. In: Solid freeform fabrication symposium 2012 Proceedings. Texas, Austin, pp 439-446

17. Mines R, Tsopanos S, Shen Y, Hasan R, McKown ST (2013) Drop weight impact behaviour of sandwich panels with metallic micro lattice cores. International Journal of Impact Engineering 60:120-132
18. Gümrük R, Mines R, Karadeniz S (2013) Static mechanical behaviours of stainless steel micro-lattice structures under different loading conditions. Materials Science \& Engineering A586:392-406

19. Yan C, Hao L, Hussein A, Young P, Raymont D (2014) Advanced lightweight $316 \mathrm{~L}$ stainless steel cellular lattice structures fabricated via selective laser melting. Mater Des 55:533-541

20. Abele E, Stoffregen HA, Kniepkamp M, Lang S, Hampe M (2015) Selective laser melting for manufacturing of thin-walled porous elements. J Mater Process Technol 215:114-122

21. Cansizoglu O, Harrysson O, West H, Cormier D, Mahale T (2008) Applications of structural optimization in direct metal fabrication. Rapid Prototyp J 14(2):114-122

22. Cardaropoli F, Alfieri V, Caiazzo F, Sergi V (2012b) Dimensional analysis for the definition of the influence of process parameters in selective laser melting of Ti-6Al-4V alloy. In: Proceedings of the Institution of Mechanical Engineers, Part B: Journal of Engineering Manufacture 226(7):1136-1142

23. I.O.f. Standardization, Mechanical testing of metals - ductility testing compression test for porous and cellular materials, first ed., in, Geneva, Switzerland, 2011

24. Kaya AC, Fleck C (2014) Deformation behavior of open-cell stainless steel foams. Materials Science \& Engineering A 615:447-456

25. McCullough KYG, Fleck NA, Ashby MF (1999) Uniaxial stressstrain behaviour of aluminium alloy foams. Acta Mater 47(8): 2323-2330

26. Castro G, Nutt SR (2012) Synthesis of syntactic steel foam using gravity-fed infiltration. Mater Sci Eng A 553:89-95

27. Queheillalt DT, Wadley HNG (2005) Cellular metal lattices with hollow trusses. Acta Mater 53(2):303-313

28. Zupan M, Chen C, Fleck NA (2003) The plastic collapse and energy absorption capacity of egg-box panels. Int J Mech Sci 45(5): $851-871$

29. Rabiei A, Vendra LJ (2009) A comparison of composite metal foam's properties and other comparable metal foams. Mater Lett 63:533-536

30. Neville BP, Rabiei A (2008) Composite metal foams processed through powder metallurgy. Mater Des 29:388-396 